\title{
High Temperature Effect on Absorption Coefficient of M-MPPs and Sandwich Structures Coupled with MPPs
}

\author{
Daliwa Joseph Bainamndi1 ${ }^{*}$, Emmanuel Siryabe², Serge Yamigno Doka1', Guy Edgar Ntamack \\ ${ }^{1}$ Groupe de Mécanique, des Matériaux et Acoustique (GMMA), Université de Ngaoundéré, Ngaoundéré, Cameroun \\ ${ }^{2}$ Safran Helicopter Engines, Groupe Evaluation Non Destructive, Bordes, France \\ Email: *bainamndidaliwa@gmail.com
}

How to cite this paper: Bainamndi, D.J., Siryabe, E., Doka, S.Y. and Ntamack, G.E. (2020) High Temperature Effect on Absorption Coefficient of M-MPPs and Sandwich Structures Coupled with MPPs. Open Journal of Acoustics, 10, 1-18.

https://doi.org/10.4236/oja.2020.101001

Received: February 29, 2020

Accepted: March 28, 2020

Published: March 31, 2020

Copyright $\odot 2020$ by author(s) and Scientific Research Publishing Inc. This work is licensed under the Creative Commons Attribution International License (CC BY 4.0).

http://creativecommons.org/licenses/by/4.0/

\begin{abstract}
This paper addresses the effect of high temperature on absorption performance of sandwich material coupled with microperforated panels (MPPs) in multiple configurations using a finite element model (FEM) over a frequency range from 10 to $3000 \mathrm{~Hz}$. The structure is backed with a rigid wall which can either be Aluminium or Al-Alloy used in aeronautic or automobile. The wave propagation in porous media is addressed using Johnson Champoux Allard model (JCA). The FEM model developed using COMSOL Multiphysics software makes it possible to predict the acoustic absorption coefficient in multilayer microperforated panels (M-MPPs) and sandwich structure. It is shown that, when structures made by MPPs or sandwich materials are submitted to high temperature, the absorption performance of the structure is strongly modified in terms of amplitude and width of the bandgap. For application in sever environment (noise reduction in engines aircrafts), Temperature is one of the parameters that will most influence the absorption performance of the structure. However, for application in the temperature domain smaller than $50^{\circ} \mathrm{C}$ (automotive applications for example), the effect of temperature is not significant on absorption performance of the structure.
\end{abstract}

\section{Keywords}

Absorption Coefficient, Finite Element Model, Microperforated Plates,

Poroelastic Core, Sandwich Structures

\section{Introduction}

During the last decades, noise became one of the important issues of daily life. Indeed, noise is omnipresent, and particularly in built-up areas. It can come 
from road, rail or air transports for example [1] [2]. Neighbourhood associations complain more and more about the level of this specific noise. In built-up countries like Europe, the European Commission is imposing some restrictive norms in terms of admitted levels of noise caused by aircrafts and automotive from various manufacturers. Engine producers and aircraft manufacturers are working daily to solve this problem [3] requiring multidisciplinary works and action in many domains such as external aero acoustics, aerodynamic, mechanics and material. Some of the materials used during the manufacture of aircraft and automotive engines by scientists and engineers are porous and sandwich material due to their attractive properties of sound absorption [4]. They are also particularly used for their lightweight constructions in aeronautics, automotive and buildings. These materials are largely exploited in aero-engine nacelles for noise reduction, where they are submitted to high temperature (between $800^{\circ} \mathrm{C}$ to $1500^{\circ} \mathrm{C}$ ), depending on the type of engines [4]. Air intakes, fan case and by pass ducts are lined wherever possible to maximize the acoustically treated area. The structure of nacelle is made by a porous facing-sheet and one or more honeycomb layers, with the overall panel being backed by a reflective solid backing sheet [5].

A sandwich structure usually consists of three layers: two thin skin plates and a thick core. Solid foams are often used as core materials, and they are either closed-cell foams, in which the fluid is isolated in discrete pockets, or open-cell foams, in which the fluid is interconnected [6]. Proper knowledge of the porous and sandwich material's characteristics allows for identifying desirable properties to design new configuration structures using specified resources, in relation to the applied technology and the purpose for use in a specific work environment [7]. It helps also to predict and analyse the most important characteristics researched through on their acoustic properties and to estimate the structure's reaction to heat.

Sandwich and porous materials for sound transmission loss (STL) have attracted numerous interests and have many configurations. The simple sandwich panel is made of double walls with an air layer inside the structure. The STL was calculated for both infinite and finite sized double walls separated by air gaps using analytical modelling and statistical energy analysis [8] [9]. To improve the sound insulation capacity, porous elastic materials are added to fill the gap between the two walls (faceplates), and the lined porous material can be either bounded or unbounded to the faceplates. Reference [10] [11], presented theoretical and numerical investigations for the transmission loss of double panels lined with porous materials, with the latter described using the Biot theory [12] [13]. They found that the highest STL could be obtained if the porous material was bounded to one faceplate and separated from the other one. Reference [14] numerically investigated the sound insulation and transmission properties of active hybrid sandwich panels with porous absorbent material layers in either active or passive mode. Compared with double panels separated by air, sandwich panels filled with porous sound absorbing materials have better sound insulation. 
However, due to their intrinsically low stiffness, the low-frequency transmission loss of sandwich panels filled with porous materials is yet sufficient.

To obtain lightweight structures with good absorption and insulation properties, combinations of MPPs and sandwich panels come into view of several researchers. An infinite MPP-solid plate coupling structure, both theoretically and experimentally was investigated [15]. A lightweight rigid-frame sandwich panel was created with perforated honeycomb corrugation hybrid core as well as perforated faceplates, which exhibited perfect sound absorption at low frequencies [16]. Reference [17] [18] presented a fully coupled modal method to calculate the STL and sound absorption coefficient (SAC) of finite flexible MPP coupled with plates. These studies demonstrated that MPP-plate sandwich structures had good STL as well as SAC. Recently, sandwich structures with honeycomb-corrugation hybrid core were studied and shown immense benefit in energy absorption and compressive strength over traditional structures [19] [20]. This research was followed by further investigation on the temperature dependency on sound absorption [21]. They studied theoretically and numerically the sound absorption performance of micro-perforated sandwich panel with perforated honeycombcorrugation hybrid core $(\mathrm{PHCH})$ and shown how dynamic viscosity and viscous boundary layer thickness increase, resulting in strengthened viscous effects in such structure when temperature rises. Adding to that, they demonstrated how at high temperatures, $\mathrm{PHCH}$ behaves best at low frequencies and possesses the broadest bandwidth compared to $\mathrm{HCH}$ and $\mathrm{PH}$.

Based on the MPP-plate coupling strategy, the goal of this present paper is to investigate the effect of high temperature on the SAC of structures that combines honeycomb sandwich panels with perforated faceplates and porous materials. Indeed, there are very few theoretical and experimental studies on the noise absorption performance of porous or sandwich materials under high temperature. Our interest is to analyse the effect of high temperatures on absorption coefficients of structures made by sandwich, MPPs or porous materials, therefore on noise reduction. Section 2 presents the mathematical models used to calculate SAC. Results and discussions are presented in section 4 and finally conclusions and prospects are given.

\section{Mathematical Background}

\subsection{Finite Element Model (FEM)}

The numerical model is built on a commercial COMSOL Multiphysics software (version 5.5) using the built-in Pressure Acoustics and Plate modules [22]. The model represents a cylindrical impedance tube set-up with two microphones to estimate the absorption coefficient. The introduction of acoustic plane wave into the tube is set up at the entrance of the tube. The configuration of plates is described in Figure 1.

According to simulations done on sandwich material [23] with the incident air, transmitted and middle fields as compressible but lossless flow, with no 


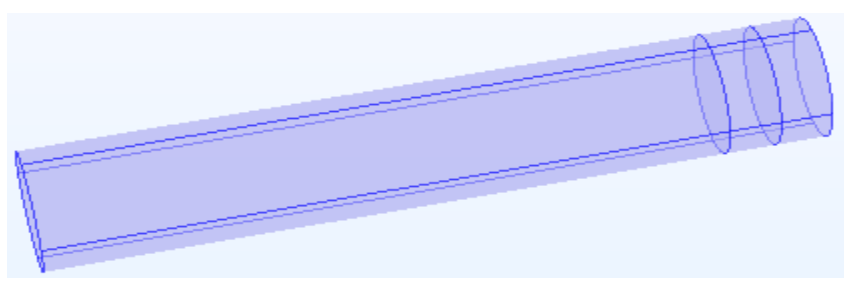

Figure 1. The Impedance Tube and plates disposition (Case B and D).

thermal conductivity and viscosity, the Helmholtz equation governing the sound pressure in the Finite Element model (FEM) is given by:

$$
\nabla^{2} p=\frac{1}{c_{0}^{2}} \frac{\partial^{2} p}{\partial t^{2}}
$$

where $p$ represents the sound pressure, $t$ the time and $c_{0}$ the sound speed in air.

The Navier Stokes (Equation (2)), the mass continuity (Equation (3)) and the heat conduction equations (Equation (4)), assuming the fluid is a perfect gas, can be expressed by the following set of equations:

$$
\begin{gathered}
i \omega \rho_{a} v=\nabla \cdot\left(-P_{t} I+\eta\left(\nabla v+(\nabla v)^{\mathrm{T}}\right)-\frac{2}{3} \eta(\nabla \cdot v) I\right) \\
i \omega \rho_{a}\left(\frac{P_{t}}{P_{0}}-\frac{T}{T_{0}}\right)+\rho_{a} \nabla \cdot v=0 \\
i \omega \rho_{a} c_{p} T=-\nabla \cdot\left(-k_{T} \nabla T\right)+i \omega P_{t}
\end{gathered}
$$

where $V$ is the fluid velocity, $P_{t}$ is the sound pressure of the thermal-acoustic field, $I$ is the identity matrix, $T$ is the temperature variation of the thermalacoustic field, $\rho_{a}$ is the air density, $\omega$ is the angular frequency, $P_{0}$ is the ambient pressure of air, $T_{0}$ is the ambient temperature, $c_{p}$ is the specific heat of air at constant pressure, $\eta$ is the dynamic viscosity of air and $k_{T}$ is the thermal conductivity of air.

The imposed pressure boundary representing the plane wave excitation incident to the MPP was employed. The sound hard representing the normal velocity vanishing at the side walls of the impedance tube and the end of the Back cavity were also employed. At the interface of the pressure acoustic field and MPP, the normal accelerations of the air and MPP are the same in the FE model, given as:

$$
\begin{gathered}
-n \cdot\left(-\frac{1}{\rho_{a}} \nabla p\right)=-n \cdot a_{n} \\
F_{p}=p n
\end{gathered}
$$

where $n$ is the surface normal direction, $a_{n}$ is the acceleration of the solid panel. $F_{p}$ is the total load of solid panel, which is decided by the normal sound pressure exerted on the panel.

While at the interface of the thermal acoustic field and pressure acoustic field, the continuous normal stress and acceleration and adiabatic conditions are ap- 
plied in the FE model as:

$$
\begin{aligned}
\left(-P_{t} I+\eta\left(\nabla v+(\nabla v)^{\mathrm{T}}\right)-\frac{2}{3} \eta(\nabla \cdot v) I\right) n=-p n \\
-n \cdot\left(-\frac{1}{\rho_{a}} \nabla p\right)=-n \cdot i \omega v \\
-n \cdot\left(k_{T} \nabla T\right)=0
\end{aligned}
$$

As to the thermal acoustic field and solid panel coupling boundary, the velocity of the air is identical to that of the solid panel and the temperature variation is isothermal at the interface of the two fields in the FE model.

To calculate the absorption coefficient $\alpha$, the two microphones method by Bodén et al. [24] is applied to the numerical model. Two microphone positions, $x_{1}$ and $x_{2}$ are chosen and the pressure values are averaged by section at these two positions as $p_{1}$ and $p_{2}$. Therefore, the absorption coefficient is calculated as:

$$
\alpha=1-|R|^{2}
$$

With the reflection coefficient given by:

$$
R=\frac{p_{2}}{p_{1}}
$$

The tube is cylindrical with a circular cross-section and has a diameter of 100 $\mathrm{mm}$, the first measuring point is placed at $x_{1}=273 \mathrm{~mm}$ from the stressed end by an acoustic pressure of $1 \mathrm{~Pa}$, the other end, $x_{2}$ delimits the depth of the air cavity after the sample and is placed at $50 \mathrm{~mm}$ from the first point of measure and from $100 \mathrm{~mm}$ from the first perforated panel. The walls of the tube are supposed to be rigid. In order to take into account, the dissipative phenomena within the porous domain, the poroacoustic domain is used for the JCA approach. The determination of the two-point pressures representing the positions of the microphones allows us to evaluate the reflection coefficient [25].

The mesh is built-in meshing tool by COMSOL [22]. The mesh size is selected as the fine level, which provides fine grid in the numerical domain. The acoustic, sandwich and MPP1 domains are meshed with tetrahedral elements for volume domain and triangular elements for surfaces boundaries as shown in Figure 2. The Complete mesh consists of 54,015 number of freedom solved for Case C, D and 66,741 for Case A, B. The computer used for our simulation has the following features: 4-core $+6 \mathrm{G}, 2.40 \mathrm{GHz}$ processor and 12 Go RAM.

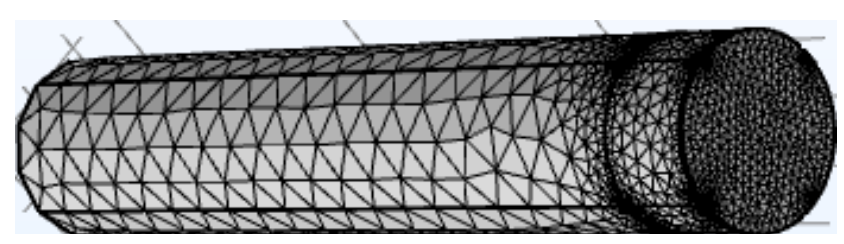

Figure 2. The mesh of the numerical geometry. 


\subsection{Perforated Plates}

The surface acoustic impedance of the $n^{\text {th }}$ layer of the perforated plates in low-sound pressure level without mean flow is given as [26]:

$$
\Gamma_{p n}=\frac{\rho_{a}}{\varepsilon_{n}} \sqrt{8 \omega \eta}\left(1+\frac{t_{p n}}{2 a_{n}}\right)+i \frac{\omega \rho_{a}}{\varepsilon_{n}}\left[\frac{8 \eta}{\omega}\left(1+\frac{t_{p n}}{2 a_{n}}\right)+t_{p n}+\delta_{n}\right]
$$

where $\rho_{a}$ is the air density, $\eta$ is the dynamic viscosity of air, $\omega$ is the angular frequency and $i=\sqrt{-1}, t_{p n}, a_{n}, \varepsilon_{n}=\pi a_{n}^{2} / b_{n}^{2}, \delta_{n}=0.85\left(2 a_{n}\right) \phi_{n}\left(\varepsilon_{n}\right)$ are the thickness, hole radius, porosity and viscous boundary layer thickness of the $n^{\text {th }}$ layer of the perforated plates respectively. $b_{n}$ is the hole pitch of the $n^{\text {th }}$ layer of the perforated plates and $\phi_{n}\left(\varepsilon_{n}\right)=1-1.47 \sqrt{\varepsilon_{n}}+0.47 \sqrt{\varepsilon_{n}^{3}}$.

\subsection{Airspaces}

The complex wave propagation constant $\gamma_{a n}$ and characteristic impedance $z_{a n}$ of airspaces can be found as:

$$
\begin{aligned}
& \gamma_{a n}=i k_{a} \\
& z_{a n}=\rho_{a} c_{0}
\end{aligned}
$$

where $k_{a}=\omega / c_{0}$ is the wave number of air and $c_{a}$ is the sound speed of air.

If the $n^{\text {th }}$ layer of airspaces is backed with a rigid wall, the surface acoustic impedance $\Gamma_{a n}$ of the $n^{\text {th }}$ layer of airspaces with the thickness $t_{p n}$ can be expressed as [27]:

$$
\Gamma_{a n}=-\rho_{a} c_{0} \cot \left(k_{a} t_{p n}\right)
$$

\subsection{Porous Material}

For homogeneous and isotropic porous materials, the acoustic impedance can be predicted by the useful empirical relations [28]. For the $n^{\text {th }}$ layer of porous materials, the empirical relations for the complex wave propagation constant $\gamma_{m n}$ and characteristic impedance $z_{m n}$ can be expressed by the flow resistivity $\sigma_{n}$ as:

$$
\begin{gathered}
\gamma_{m n}=k_{a}\left\{c_{5 n}\left(f \rho_{a} / \sigma_{n}\right)^{c_{6 n}}+i\left[1+c_{7 n}\left(f \rho_{a} / \sigma_{n}\right)^{c_{8 n}}\right]\right\} \\
z_{m n}=\rho_{a} c_{0}\left\{\left[1+c_{1 n}\left(f \rho_{a} / \sigma_{n}\right)^{c_{2 n}}\right]-i\left[c_{3 n}\left(f \rho_{a} / \sigma_{n}\right)^{c_{4 n}}\right]\right\}
\end{gathered}
$$

where $f$ is the sound frequency, $c_{1 n}, c_{2 n}, \cdots, c_{8 n}$ are the material constants for the $n^{t h}$ layer of porous materials. If the $n^{t h}$ layer of porous materials is backed with a rigid wall, the surface acoustic impedance $\Gamma_{m n}$ of the $n^{\text {th }}$ layer of porous materials with the thickness $t_{m n}$ can be expressed as [29]:

$$
\Gamma_{m n}=z_{m n} \operatorname{coth}\left(\gamma_{m n} t_{m n}\right)
$$

\subsection{Johnson Champoux Allard Model (JCA)}

The JCA model gives the expressions for the dynamic effective densities and bulk modulus of a porous material saturated by a fluid of density $\rho_{a}$ and bulk modulus $K_{0}$ considering a rigid frame. The poroelastic material is characte- 
rized by its porosity $\varepsilon_{n}$, its tortuosity $\alpha_{\infty}$, its flow resistivity $\eta$, static resistivity of air $\sigma$ and the thermal and viscous characteristic lengths $\Lambda$ and $\Lambda_{0}$, respectively. Table 1 gives the values of the static physical parameters of the porous material used in this work. The dynamic effective density and bulk modulus given by:

$$
K_{P}=\frac{\rho_{p}=\alpha_{\infty} \rho_{a}\left[1-i \frac{\sigma \varepsilon_{n}}{\omega \rho_{a} \alpha_{\infty}} \sqrt{\left.1+i \frac{4 \alpha_{\infty}^{2} \eta \rho_{a} \omega}{\sigma^{2} \Lambda^{2} \varepsilon_{n}^{2}}\right]}\right.}{\gamma-(\gamma-1)\left[1-i \frac{8 \eta}{\Lambda^{\prime 2} \operatorname{Pr} \omega \rho_{a}} \sqrt{1+i \frac{\rho_{a} \omega \operatorname{Pr} \Lambda^{\prime 2}}{16 \eta}}\right]^{-1}}
$$

Table 1. The Inputs data for simulations of the different configurations with the same total thickness of $\mathbf{5 4 . 6} \mathrm{mm}$ for the Case B and D and $\mathbf{2 7 . 4} \mathrm{mm}$ for Case A and C [30]

\begin{tabular}{|c|c|c|c|c|c|}
\hline Material & Poroelastic cor & Aluminium & Al-alloys & MPP1 & Air \\
\hline Young's modulus $(E),[\mathrm{Pa}]$ & $414 \times 10^{3}$ & $70 \times 10^{9}$ & $73.1 \times 10^{9}$ & & \\
\hline Density $(\rho)\left[\mathrm{kg} / \mathrm{m}^{3}\right]$ & 57 & 2700 & 2780 & - & - \\
\hline $\begin{array}{l}\text { Thermal conductivity }\left(k_{t}\right) \\
{[\mathrm{W} /(\mathrm{m} \cdot \mathrm{K})]}\end{array}$ & - & - & - & - & 0.026 \\
\hline Prandt Number $(P r)$ & - & - & - & - & 0.71 \\
\hline Air Density $\left(\rho_{a}\right)\left[\mathrm{kg} / \mathrm{m}^{3}\right]$ & - & - & - & - & 1.21 \\
\hline Ambient Pressure $\left(P_{0}\right)[\mathrm{Pa}]$ & - & - & - & - & 101,325 \\
\hline Dynamic viscosity $(\eta)[$ Pa.s] & - & - & - & - & $1.81 \times 10^{-5}$ \\
\hline Speed of sound $\left(c_{0}\right)[\mathrm{m} / \mathrm{s}]$ & - & - & - & - & 343 \\
\hline Specific heat $\left(c_{p}\right)[\mathrm{J} /(\mathrm{kg} \cdot \mathrm{K})]$ & - & - & - & - & 1004 \\
\hline Poisson ratios $\left(v_{c}\right)[-]$ & 0.24 & 0.33 & - & - & - \\
\hline Frame loss factor $\left(\eta_{c}\right)[-]$ & 0.19 & 0.01 & - & - & - \\
\hline $\begin{array}{l}\text { Statistic flow resistivity }(\sigma) \\
{\left[\mathrm{N} . \mathrm{s} / \mathrm{m}^{4}\right]}\end{array}$ & $55 \times 10^{3}$ & $4.43 \times 10^{3}$ & - & - & - \\
\hline Specific ratio $(\gamma)$ & - & - & - & - & 1.4 \\
\hline Tortuosity $\left(\alpha_{\infty}\right)[-]$ & 1.05 & - & - & - & - \\
\hline Porosity $\varepsilon_{n}[-]$ & 0.95 & & - & 0.022 & - \\
\hline $\begin{array}{l}\text { Viscous characteristic length }(\Lambda) \\
{[\mu \mathrm{m}]}\end{array}$ & 37 & - & - & - & - \\
\hline $\begin{array}{l}\text { Thermal characteristic length }\left(\Lambda^{\prime}\right) \\
{[\mu \mathrm{m}]}\end{array}$ & 120 & - & - & - & - \\
\hline Perforations radius $a_{n}[\mathrm{~mm}]$ & - & - & - & 0.5 & - \\
\hline MPP thickness $t_{p n}[\mathrm{~mm}]$ & - & - & - & 1 & - \\
\hline Skin thickness layer $h[\mathrm{~mm}]$ & - & - & - & 0.2 & - \\
\hline Core/Air cavity $H[\mathrm{~mm}]$ & - & - & - & 27 & - \\
\hline
\end{tabular}
[31]. 


\section{Material for Our Simulation}

To make our sandwich panel with layers made of face sheets of MPPs, we needed one configuration of poroelastic core (PC) used as core material. The thickness of the skin of sandwich material (or sheet) is $0.2 \mathrm{~mm}$ and the rigid wall which can be Aluminum or Al-alloy backing the whole structure has thickness of $1 \mathrm{~mm}$. Alloy materials in aircraft industries are special metal material. They are subjected to stress and strain excitation because their energy are consumed as a result of a magnetoelastic effect, grain boundary effect, and so on. And the loss factor of damping alloys is large for good damping properties [30]. The airgap which can be filled by core in all cases of our study has a thickness of $27 \mathrm{~mm}$. We used one MPP with its characteristics listed in Table 1. The sandwich material with three layers composed of two thin skin plates and a thick core then its face sheets made by MPP is given in Figure 3.

First, a structure made by one, two, three and four MPPs with air cavities or porous materials were considered and the effect of temperature was analysed. Then four types of configuration made by sandwich materials are considered. They are described in Figure 4 according to each case.

The parameters associated with the panel system are taken as those in previous studies of double wall sandwich panels lined with poroelastic material [31] [32]. The property parameters are listed in Table 1 . The ambient air properties in our study are the same as those of standard atmosphere.

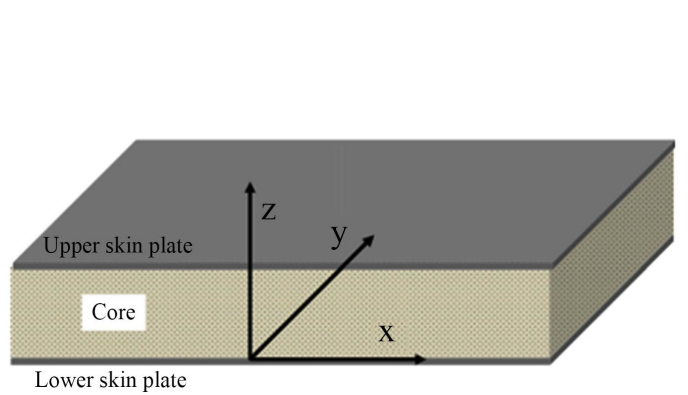

(a)

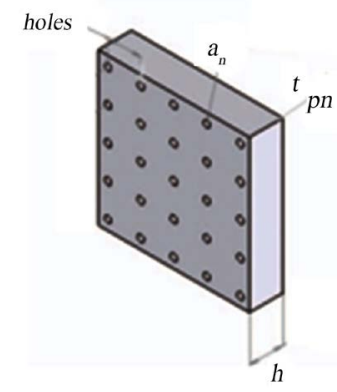

(b)

Figure 3. The sandwich material coupled with MPP.

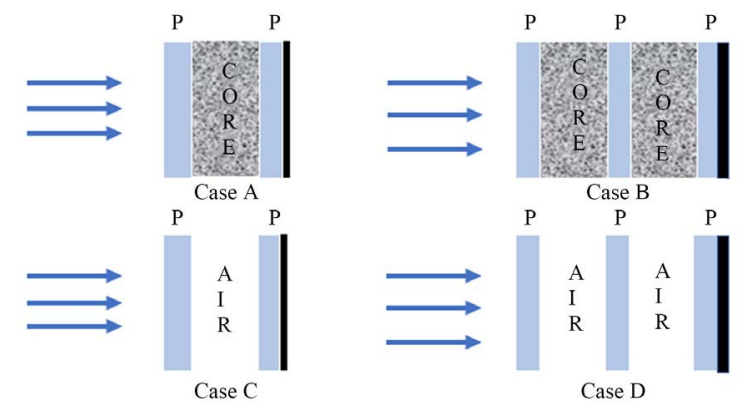

Figure 4. The configuration of sandwich material used in our simulations: Case A. With poroelastic core backed with a rigid wall; Case B. With two poroelastic core between three microperforated panels and backed by a rigid wall. Case C and D are similar to previous cases but filled with air. 


\section{Results and Discussions}

In this section, the effect of temperature is analysed on structures made by one, two, three and four MPPs with air cavities or porous materials and backed with rigid wall. Then, the cases of structures made by sandwich materials are considered.

\subsection{Effect of Temperature on Acoustic Performances of M-MPPs}

\subsubsection{Acoustic Performances of Structure Made by One MPP}

Figure 5(a) shows the acoustic absorption of structure made by one MPP and one air cavity backed with a rigid wall, for different temperatures: $20^{\circ} \mathrm{C}, 45^{\circ} \mathrm{C}$, $800^{\circ} \mathrm{C}$ and $960^{\circ} \mathrm{C}$. We observed a shift of the absorption coefficient to higher frequency by increasing temperatures from $20^{\circ} \mathrm{C}$ to $960^{\circ} \mathrm{C}$. The maximum frequency shifts of the peak of absorption coefficient produced by the change in temperature is around $\Delta f=1170 \mathrm{~Hz}$. A decrease in amplitude of the absorption coefficient when temperature increase is also observed. The amplitude of absorption coefficient goes from 0.66 for $20^{\circ} \mathrm{C}$ to 0.54 for $960^{\circ} \mathrm{C}$, either a relative variation of $-18.18 \%$. For this case, acoustic absorption performance is reducing by increasing temperature.

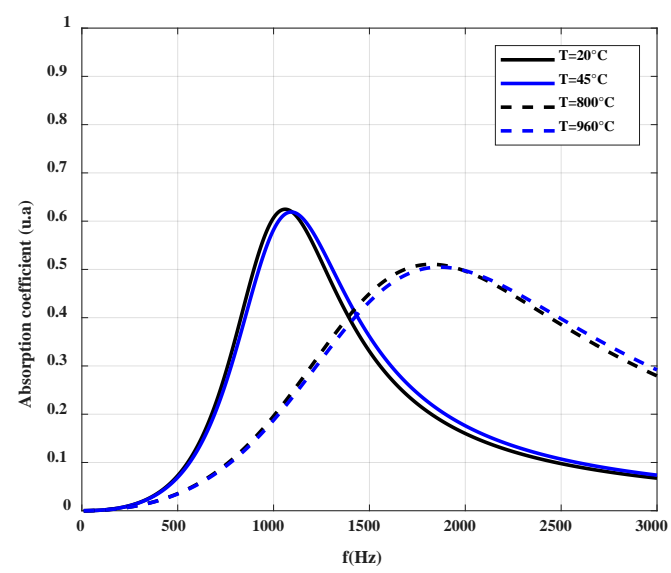

(a)

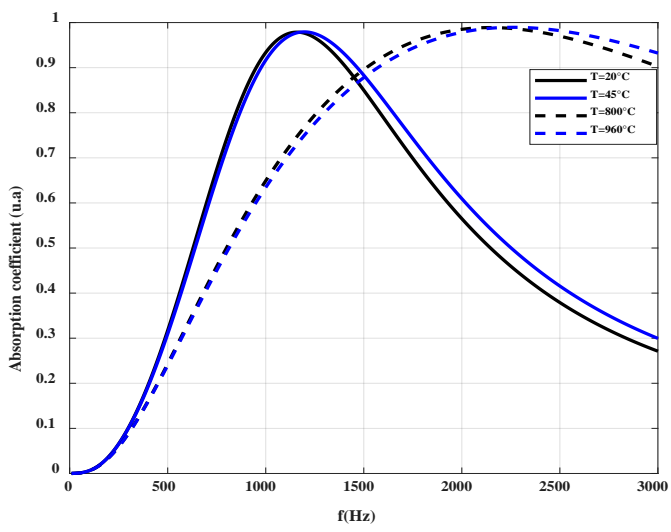

(b)

Figure 5. The effect of temperature on the absorption coefficient for a structure made by one MPP with (a) air cavity and (b) poroelastic core. 
The structure made by one MPP and one air cavity filled with porous material (poroelastic core) and backed with a rigid wall is now analyse in Figure 5(b). We observed that, the presence of porous materials increases the performances in term of amplitudes and width of the spectrum of the absorption coefficient. The acoustic absorption band is broadened when the temperature increases. As previously, a shift of the absorption coefficient to higher frequency by increasing temperatures from $20^{\circ} \mathrm{C}$ to $960^{\circ} \mathrm{C}$ is also observed. The maximum frequency shifts of the peak of absorption coefficient produce by the change in temperature is around $\Delta f=1100 \mathrm{~Hz}$. A very small increase in amplitude of the absorption coefficient when temperature increase is observed. The amplitude of absorption coefficient goes from 0.9 for $20^{\circ} \mathrm{C}$ to 0.97 for $960^{\circ} \mathrm{C}$, either a relative variation of $+7.2 \%$. In this case, the acoustic absorption performance is enhanced by increasing temperature.

With the above sound absorption coefficient, it can be noticed that the fluid velocity is affected by the temperature. When the temperature increases, the air viscosity increases too, which increases the flow resistance.

\subsubsection{Acoustic Performances of Structure Made by two MPPs}

In this section, the acoustic absorption of structure made by two MPPs and two air cavities or porous materials and backed with a rigid wall are considered. Figure 6(a) presents the effect of temperature on structure made by two MPPs and air cavities. We can observe a shift of the absorption coefficient to higher frequency by increasing temperatures from $20^{\circ} \mathrm{C}$ to $960^{\circ} \mathrm{C}$. From $20^{\circ} \mathrm{C}$ to $45^{\circ} \mathrm{C}$ two peaks in the absorption coefficient are identified, while from $800^{\circ} \mathrm{C}$ to $960^{\circ} \mathrm{C}$ we have only one peak, in the range of frequencies studied. The maximum frequency shifts of the first peak of absorption coefficient produce by the change in temperature is around $\Delta f=651 \mathrm{~Hz}$. A decrease in amplitude of the absorption coefficient when temperatures increase is also observed. The amplitude of absorption coefficient goes from 0.71 for $20^{\circ} \mathrm{C}$ to 0.61 for $960^{\circ} \mathrm{C}$ (for the first peak), either a relative variation of $-16.39 \%$. For this case, acoustic absorption performance is also reducing by increasing temperature.

In Figure 6(b), the structure made by two MPPs and two air cavities filled with porous material (poroelastic core) and backed with a rigid wall is analysed. As we can see, the presence of poroelastic core material influences the shape and the performances in terms of amplitudes and width of the spectrum of the absorption coefficient. The acoustic absorptions of each curve are similar with the nearly same amplitude in the range of the frequency $<855 \mathrm{~Hz}$. For frequencies $>$ $855 \mathrm{~Hz}$, the amplitude of the absorption coefficient resulting from high temperature increases and those of the small temperature (between $20^{\circ} \mathrm{C}$ to $45^{\circ} \mathrm{C}$ ) decreases. The amplitude of absorption coefficient goes from 0.84 for $20^{\circ} \mathrm{C}$ to 0.95 for $960^{\circ} \mathrm{C}$, either a relative variation of $+11.57 \%$. In this case, the acoustic absorption performance is enhanced by increasing temperature. The increases of temperature and presence of the poroelastic core within the structure is therefore interesting for high frequencies $(>855 \mathrm{~Hz})$. 


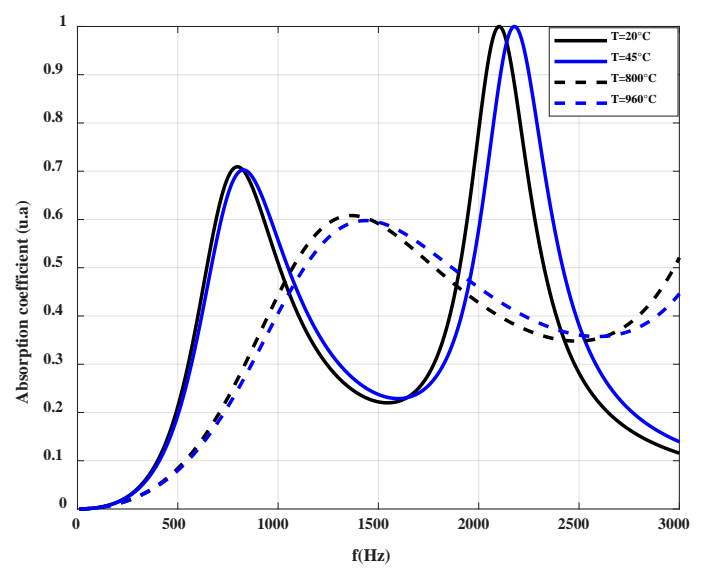

(a)

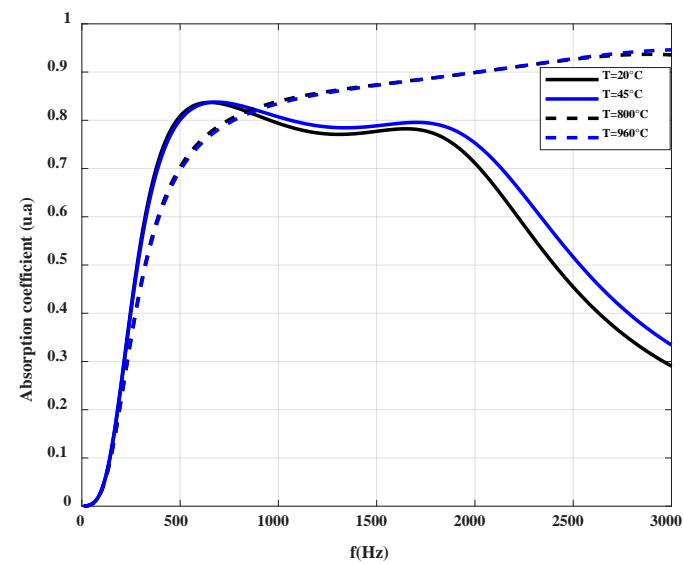

(b)

Figure 6. The effect of temperature on the absorption coefficient for a structure made by two MPPs with (a) air cavity and (b) poroelastic core.

\subsubsection{Acoustic Performances of Structure Made by Three MPPs}

Now we consider the case of a structure made by three MPPs and three air cavities or porous materials and backed with a rigid wall. Figure 7(a) presents the effect of temperature on structure made by three MPPs and air cavities. We observe a shift of the absorption coefficient to higher frequency by increasing temperatures from $20^{\circ} \mathrm{C}$ to $960^{\circ} \mathrm{C}$. From $20^{\circ} \mathrm{C}$ to $45^{\circ} \mathrm{C}$ three peaks in the absorption coefficient are identified, while from $800^{\circ} \mathrm{C}$ to $960^{\circ} \mathrm{C}$ we have only two peaks. The maximum frequency shift is observed on the second peak of absorption coefficient and is around $\Delta f=1585 \mathrm{~Hz}$. A decrease in amplitude of the absorption coefficient when temperatures increase is also observed. The amplitude of absorption coefficient goes from 0.77 for $20^{\circ} \mathrm{C}$ to 0.67 for $960^{\circ} \mathrm{C}$ (for the first peak), either a relative variation of $-12.98 \%$. For this case, acoustic absorption performance is also reducing by increasing temperature.

In Figure 7(b), the structure made by three MPPs and three air cavities filled with porous material (poroelastic core) and backed with a rigid wall is analysed. As we can see, the presence of poroelastic core material influence the shape and 


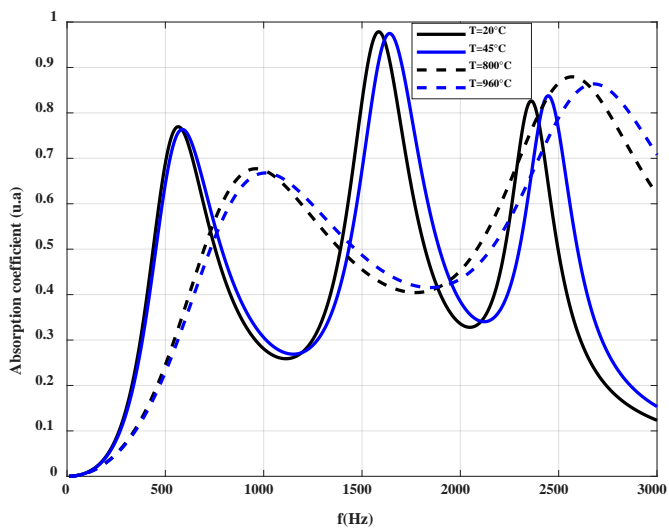

(a)

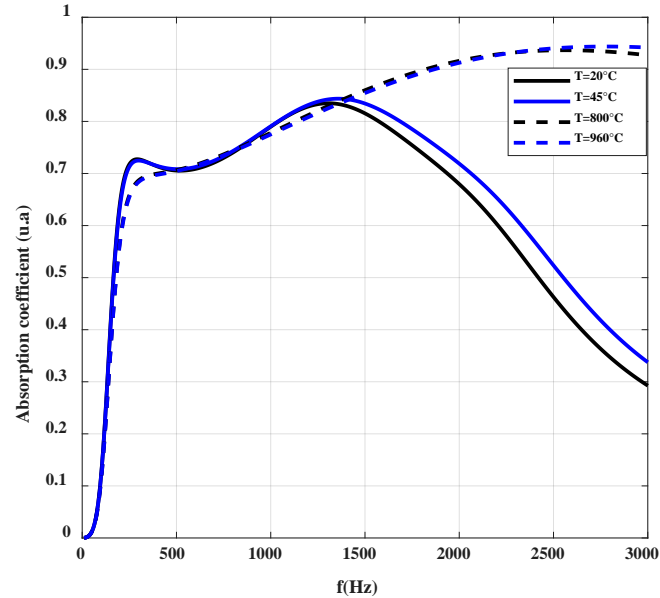

(b)

Figure 7. The effect of temperature on the absorption coefficient for a structure made by three MPPs with (a) air cavity and (b) poroelastic core.

the performances in terms of amplitudes and width of the spectrum of the absorption coefficient. The acoustic absorptions of each curve are similar with the nearly same amplitude in the range of the frequency $<1500 \mathrm{~Hz}$. For frequencies $>$ $1500 \mathrm{~Hz}$, the amplitude of the absorption coefficient resulting from high temperature increases and those of the small temperature (between $20^{\circ} \mathrm{C}$ to $45^{\circ} \mathrm{C}$ ) decreases. The amplitude of absorption coefficient goes from 0.72 for $20^{\circ} \mathrm{C}$ to 0.94 for $960^{\circ} \mathrm{C}$, either a relative variation of $+23.40 \%$. In this case, the acoustic absorption performance is enhanced by increasing temperature. The increases of temperature and presence of the poroelastic core within the structure is therefore interesting for high frequencies $(>1500 \mathrm{~Hz})$.

\subsubsection{Acoustic Performances of Structure Made by Four MPPs}

The case of a structure made by four MPPs and four air cavities or porous materials and backed with a rigid wall is considered. As for the previous case of Figure 7(a), we also observed a shift of the absorption coefficient to high frequency by increasing temperatures from $20^{\circ} \mathrm{C}$ to $960^{\circ} \mathrm{C}$. From $20^{\circ} \mathrm{C}$ to $45^{\circ} \mathrm{C}$ four peaks 
in the absorption coefficient are identified, while from $800^{\circ} \mathrm{C}$ to $960^{\circ} \mathrm{C}$ we have only three peaks (see Figure 8(a)). The structure made by four MPPs and four air cavities filled with porous material (poroelastic core) and backed with a rigid wall is also analysed Figure 8(b). As we can see, the presence of poroelastic core material influence the shape and the performances in term of amplitudes and width of the spectrum of the absorption coefficient. The acoustic absorptions of each curve are similar with the nearly same amplitude in the range of the frequency $<1000 \mathrm{~Hz}$. For frequencies $>1000 \mathrm{~Hz}$, the amplitude of the absorption coefficient resulting from high temperature increases and those of the small temperature (between $20^{\circ} \mathrm{C}$ to $45^{\circ} \mathrm{C}$ ) decreases. The amplitude of absorption coefficient of the first peaks is equal different frequencies: 0.82 at $444 \mathrm{~Hz}$ for $20^{\circ} \mathrm{C}$ and $45^{\circ} \mathrm{C}$ and at $625 \mathrm{~Hz}$ for $800^{\circ} \mathrm{C}$ and $960^{\circ} \mathrm{C}$. The amplitude of the absorption coefficient when the structure is filled with poroelastic core for the second peak goes from 0.82 for $20^{\circ} \mathrm{C}$ to 0.94 for $960^{\circ} \mathrm{C}$, either a relative variation of $+12.76 \%$. In this case, the acoustic absorption performance is enhanced by increasing temperature. The increases of temperature and presence of the poroelastic core within the structure is therefore interesting for high frequencies $(>1000 \mathrm{~Hz})$.

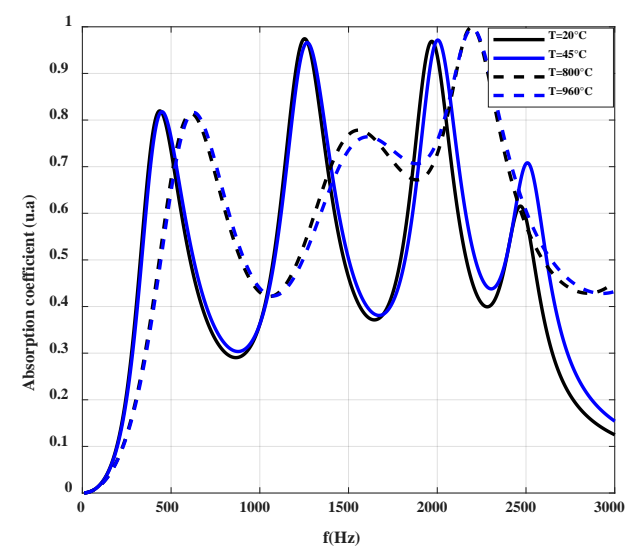

(a)

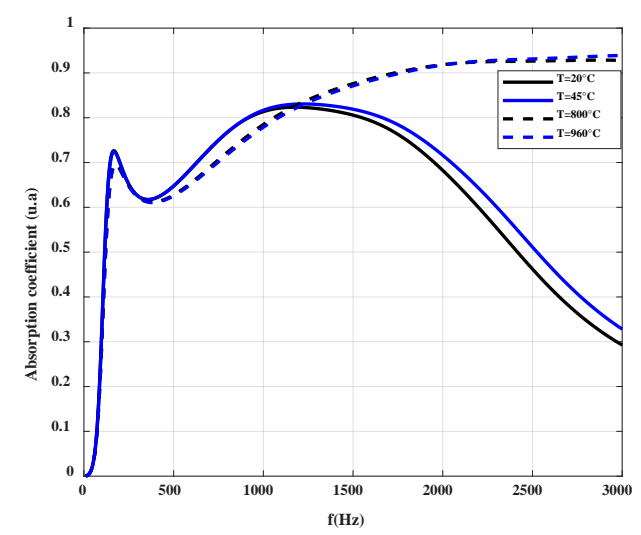

(b)

Figure 8. The effect of temperature on the absorption coefficient for a structure made by four MPPs with (a) air cavity and (b) poroelastic core. 


\subsection{Effect of Temperature on Acoustic Performance of Sandwich Materials}

In this section, structures made by sandwich materials (listed in Figure 4) are analysed.

\subsubsection{Acoustic Performance for Case $C$ and $D$}

The structures in case $\mathrm{C}$ and $\mathrm{D}$ are firstly considered and the effect of temperature is analysed. In these two cases sandwich materials have MPP as upper and lower face filled with air. Figure 9(a) shows the acoustic absorption curves of sandwich structure in case $\mathrm{C}$. We observe a shift of the absorption coefficient to high frequency by increasing temperatures from $20^{\circ} \mathrm{C}$ to $960^{\circ} \mathrm{C}$. The maximum frequency shifts of the peak of absorption coefficient produced by the change in temperature is around $\Delta f=600 \mathrm{~Hz}$. A decrease in amplitude of the absorption coefficient when temperature increases is also observed. The amplitude of absorption coefficient goes from 0.62 for $20^{\circ} \mathrm{C}$ to 0.5 for $960^{\circ} \mathrm{C}$, either a relative variation of $-19.3 \%$. For this case, acoustic absorption performance (in terms of amplitude of absorption) is reducing by increasing temperature. However, the acoustic absorption band is broadened when the temperature increases. The case D (Figure 9(b)), we also observe that the acoustic absorption band is broadened when the temperature increases. As previously, a shift of the absorption coefficient to higher frequency by increasing temperatures from $20^{\circ} \mathrm{C}$ to $960^{\circ} \mathrm{C}$ is also observed. The maximum frequency shifts of the peak of absorption coefficient produced by the change in temperature is around $\Delta f=550 \mathrm{~Hz}$. However, the amplitude of the absorption coefficient when temperature increases remain constant. In this case, the acoustic absorption performance remains constant, with a large broadband. In general, the absorption coefficients obtained for cases $\mathrm{C}$ and D are similar to those of Figure 5(a) and Figure 5(b), respectively.

\subsubsection{Acoustic Performance for Case $A$ and $B$}

We consider now the cases A and B. In Figure 10(a) we observe a shift of the absorption coefficient to higher frequency by increasing temperatures from $20^{\circ} \mathrm{C}$ to $960^{\circ} \mathrm{C}$. The maximum frequency shifts of the first peak of absorption coefficient produced by the change in temperature is around $\Delta f=1000 \mathrm{~Hz}$. A decrease in amplitude of the absorption coefficient when temperature increases is also observed. The amplitude of absorption coefficient (second peak) goes from 1 for $20^{\circ} \mathrm{C}$ to 0.89 for $960^{\circ} \mathrm{C}$ (for the first peak), either a relative variation of $-12.35 \%$. For this case, acoustic absorption performance is reducing in terms of amplitude by increasing temperature. In Figure 10(b), the case B is analysed. The acoustic absorptions of each curve are similar with the nearly same amplitude in the range of the frequency $<1500 \mathrm{~Hz}$. For frequencies $>1500 \mathrm{~Hz}$, the amplitude of the absorption coefficient resulting from high temperature increases and those of the lower temperature (between $20^{\circ} \mathrm{C}$ to $45^{\circ} \mathrm{C}$ ) decreases. The amplitude of absorption coefficient goes from 0.72 for $20^{\circ} \mathrm{C}$ to 0.95 for $960^{\circ} \mathrm{C}$, either a relative variation of $+24.21 \%$. In this case, the acoustic absorption performance is enhanced by increasing temperature. The increases of temperature and presence of 
the poroelastic core within the structure is therefore interesting for high frequencies $(>1500 \mathrm{~Hz})$. In general, the absorption coefficients obtained for cases A and B are the combination of Figure 6(a) and Figure 7(a) (for case A) and Figure 6(b) and Figure 7(b) (for case B), respectively.

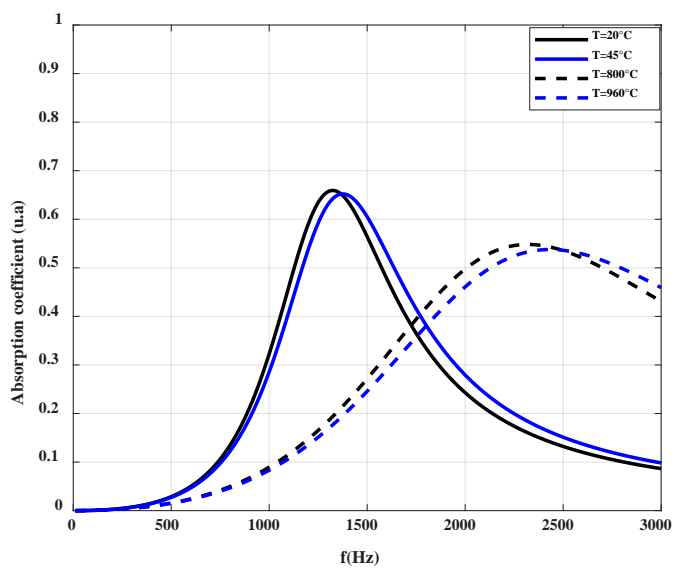

(a)

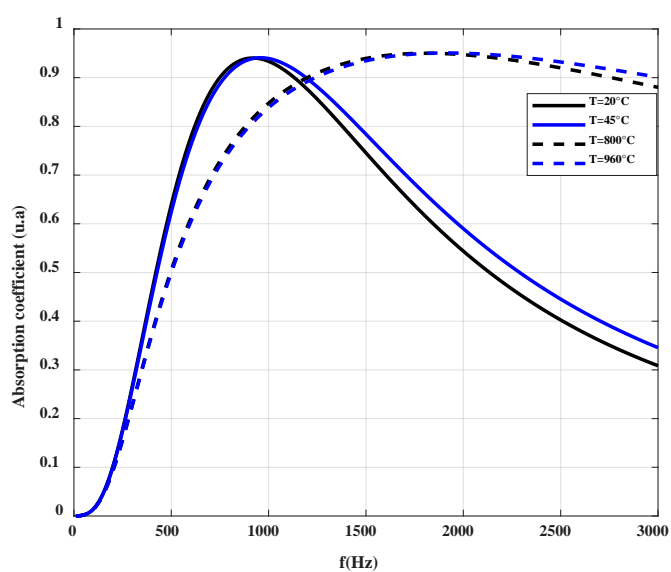

(b)

Figure 9. The effect of temperature on the absorption coefficient for (a) Case C and (b) Case D.

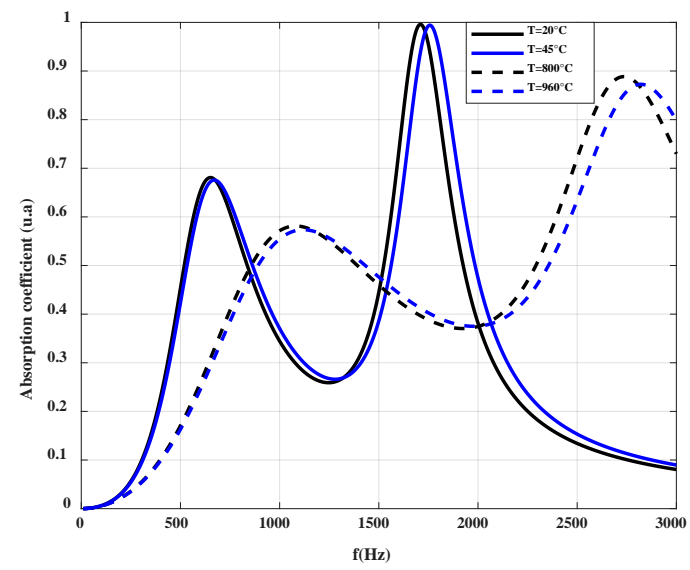

(a) 


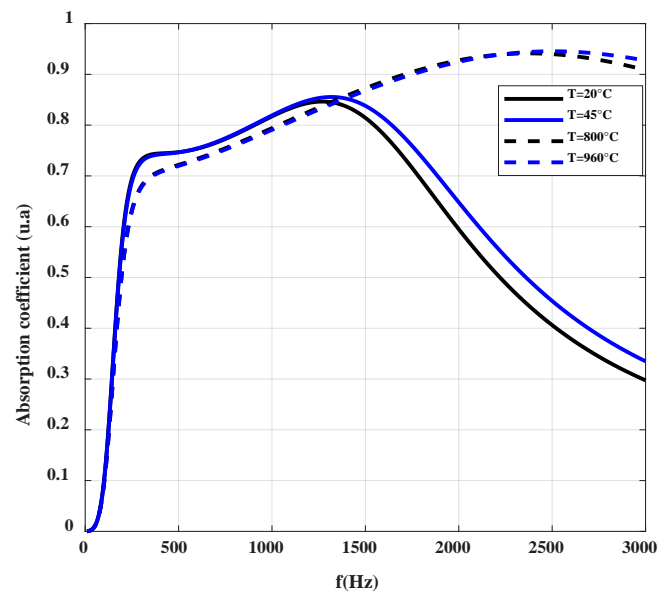

(b)

Figure 10. The effect of temperature on the absorption coefficient for (a) Case A and (b) Case B.

\section{Conclusion}

This study reveals the effect of temperature on the absorption coefficient. Two different approaches were used with MPPs and sandwich structures filled with air and poroelastic core using FE model. Increasing temperatures from $20^{\circ} \mathrm{C}$ to $960^{\circ} \mathrm{C}$ lead to the shift of the absorption coefficient to higher frequency and a decrease or an increase (depending on the configuration for MPPs or sandwich with air or poroelastic core) in amplitude of the absorption coefficient. Therefore, when structures made by MPPs or sandwich materials are submitted to high temperatures, the absorption performance of the structure is strongly modified in terms of amplitude, position of the peaks and width of the bandgap. For applications submitted in environment (greater than $500^{\circ} \mathrm{C}$ ), the temperature is one of the parameters that will most influence the absorption performance of the structure. However, for application in the temperature domain lesser than $50^{\circ} \mathrm{C}$, the effect of temperature is not significant on absorption performance of the structure. The highest absorption coefficient achieved by the structure is equal to 1; a level researched by constructors of automotive and aircraft engines. During the manufacturing of the structure, the varying characteristics of acoustic parameters with temperature and frequency must be considered.

\section{Conflicts of Interest}

The authors declare no conflicts of interest regarding the publication of this paper.

\section{References}

[1] Gagliardi, P., Teti, L. and Licitra, G. (2018) A Statistical Evaluation on Flight Operational Characteristics Affecting Aircraft Noise during Take-Off. Applied Acoustics, 134, 8-15. https://doi.org/10.1016/j.apacoust.2017.12.024

[2] Filippone, A. (2014) Aircraft Noise Prediction. Progress in Aerospace Sciences, 68, 27-63. https://doi.org/10.1016/j.paerosci.2014.02.001 
[3] Florin, P.F., Gasser, S. and Leylekian, L. (2003) Design of Materials for Noise Reduction in Aircraft Engines. Aerospace Science and Technology, 7, 63-72. https://doi.org/10.1016/S1270-9638(02)00006-8

[4] Gupta, N. and Woldesenbet, E. (2005) Characterization of Flexural Properties of Syntactic Foam Core Sandwich Composites and Effect of Density Variation. Journal of Composite Materials, 39, 2197-2212. https://doi.org/10.1177/0021998305052037

[5] Ferrante, P., Roeck, W.D., Desmet, W. and Magnino, N. (2016) Back to Back Comparison of Impedance Measurement Techniques Applied to the Characterization of Aero-Engine Nacelle Acoustic Liners. Applied Acoustics, 105, 129-142. https://doi.org/10.1016/j.apacoust.2015.12.004

[6] Daniel, I.M., Gdoutos, E.E., Abot, J.L. and Wang, K.A. (2003) Deformation and Failure of Composite Sandwich Structures. Journal of Thermoplastic Composite Materials, 16, 345-364. https://doi.org/10.1177/0892705703016004005

[7] CY, C., PH, L. and CH, L. (2008) Vibration Cover Acoustic Impedance of Porous Sound Absorption Material. Republic of China Vibration and Noise Association of Engineering Thesis Album, 394-496.

[8] Wang, T., Li, S., Rajaram, S. and Nutt, S.R. (2010) Predicting the Sound Transmission Loss of Sandwich Panels by Statistical Energy Analysis Approach. Journal of Vibration and Acoustics, 132, Article ID: 011004. https://doi.org/10.1115/1.4000459

[9] Sun, W. and Liu, Y. (2016) Vibration Analysis of Hard-Coated Composite Beam Considering the Strain Dependent Characteristic of Coating Material. Acta Mecha Sinica, 32, 731-742. https://doi.org/10.1007/s10409-016-0564-4

[10] Bolton, J.S. and Green, E.R. (1993) Normal Incidence Sound Transmission through Double-Panel Systems Lined with Relatively Stiff, Partially Reticulated Polyurethane Foam. Applied Acoustics, 39, 23-51. https://doi.org/10.1016/0003-682X(93)90028-5

[11] Bolton, J.S., Shiau, N.M. and Kang, Y.J. (1996) Sound Transmission through Multi-Panel Structures Lined with Elastic Porous Materials. Journal of Sound and Vibration, 191, 317-347. https://doi.org/10.1006/jsvi.1996.0125

[12] Biot, M.A. (1956) Theory of Propagation of Elastic Waves in a Fluid-Saturated Porous Solid. I. Low-Frequency Range. The Journal of the Acoustical Society of America, 28, 168-178. https://doi.org/10.1121/1.1908239

[13] Biot, M.A. (1956) Theory of Propagation of Elastic Waves in a Fluid-Saturated Porous Solid. II. Higher Frequency Range. The Journal of the Acoustical Society of America, 28, 179-191. https://doi.org/10.1121/1.1908241

[14] Hu, Y., Galland, M.A. and Chen, K. (2012) Acoustic Transmission Performance of Double-Wall Active Sound Packages in a Tube: Numerical/Experimental Validations. Applied Acoustics, 73, 323-337. https://doi.org/10.1016/j.apacoust.2011.10.003

[15] Dupont, T., Pavic, G. and Laulagnet, B. (2003) Acoustic Properties of Lightweight Microperforated Plate Systems. Acta Acustica United with Acustica, 89, 201-212. https://www.ingentaconnect.com/content/dav/aaua/2003/00000089/00000002/art00 001 ? crawler=true\# expand/collapse

[16] Tang, Y., Li, F., Xin, F.X. and Lu, T.J. (2017) Heterogeneously Perforated Honeycomb-Corrugation Hybrid Sandwich Panel as Sound Absorber. Materials \& Design, 134, 502-512. https://doi.org/10.1016/j.matdes.2017.09.006

[17] Bravo, T., Maury, C. and Pinhède, C. (2012) Sound Absorption and Transmission through Flexible Micro-Perforated Panels Backed by an Air Layer and a Thin Plate. The Journal of the Acoustical Society of America, 131, 3853-3863.

https://doi.org/10.1121/1.3701987 
[18] Bravo, T., Maury, C. and Pinhède, C. (2013) Enhancing Sound Absorption and Transmision through Flexible Multi-Layer Micro-Perforated Structures. The Journal of the Acoustical Society of America, 134, 3663-3673. https://doi.org/10.1121/1.4821215

[19] Han, B., Qin, K., Yu, B., Zhang, Q. and Lu, T.J. (2015) Honeycomb-Corrugation Hybrid as a Novel Sandwich Core for Significantly Enhanced Compressive Performance. Material and Design, 93, 271-282. https://doi.org/10.1016/j.matdes.2015.12.158

[20] Han, B., Wang, W., Zhang, Z., Zhang, Q., Jin, F. and Lu, T. (2016) Performance Enhancement of Sandwich Panels with Honeycomb-Corrugation Hybrid Core. Theoretical and Applied Mechanics Letters, 6, 54-59. https://doi.org/10.1016/j.taml.2016.01.001

[21] Tang, Y., Xin, F. and Lu, T.J. (2019) Sound Absorption of Micro-Perforated Sandwich Panel with Honeycomb Corrugation Hybrid Core at High Temperatures. Composite Structures, 226, Article ID: 111285. https://doi.org/10.1016/j.compstruct.2019.111285

[22] Melling, T.H. (1973) The Acoustic Impedance of Perforates at Medium and High Sound Pressure Levels. Journal of Sound and Vibration, 29, 1-65. https://doi.org/10.1016/S0022-460X(73)80125-7

[23] Meng, H. (2017) Acoustic Properties of Novel Multifunctional Sandwich Structures and Porous Absorbing Materials. PhD Thesis, Lyon, 11-12.

[24] Bodén, H. and Åbom, M. (1986) Influence of Errors on the Two-Microphone Method for Measuring Acoustic Properties in Ducts. The Journal of the Acoustical Society of America, 79, 541. https://doi.org/10.1121/1.393542

[25] Bonfiglio, P., Pompoli, F. and Fioni, F. (2009) Simulazione FEM di sistemiforati. Proceedings of 36 th Italian Acoustics Association Conference, Turin.

[26] Jinkyo, L., George, W. and Swenson, J. (1992) Compact Sound Absorbers for Low Frequencies. Noise Control Engineering Journal, 38, 109-117. https://doi.org/10.3397/1.2827811

[27] Delany, M.E. and Bazeley, E.N. (1970) Acoustic Properties of Porous Absorbent Material. Applied Acoustics, 3, 105-116. https://doi.org/10.1016/0003-682X(70)90031-9 https://www.math2market.com/Publications/1970Delany-Bazley.pdf

[28] Dunn, I.P. and Davern, W.A. (1986) Calculation of Acoustic Impedance of MultiLayer Absorbers. Applied Acoustics, 19, 321-334. https://doi.org/10.1016/0003-682X(86)90044-7

[29] Biot, M.A. (1941) General Theory of Three-Dimensional Consolidation. Journal of Applied Physics, 12, 155-164. https://doi.org/10.1063/1.1712886

[30] Jian, P. (2019) Noise and Vibration Control in Automotive Bodies. John Wiley \& Sons Ltd., Chichester.

[31] Shen, C., Zhang, H. and Liu, Y. (2019) Analytical Modelling of Sound Transmission Loss across Finite Clamped Triple-Wall Sandwich Panels in the Presence of External Mean Flow. Applied Mathematical Modelling, 73, 146-165. https://doi.org/10.1016/j.apm.2019.03.043

[32] Meng, H., Galland, M.A. and Ichchou, M. (2017) Small Perforations in Corrugated Sandwich Panel Significantly Enhance Low Frequency Sound Absorption and Transmission Loss. Composite Structures, 182, 1-11. https://doi.org/10.1016/j.compstruct.2017.08.103 